\title{
Thormation
}

Nordic Journal of Art and Research

ISSN: 1893-2479

www.artandresearch.info

\section{Assessing dance: \\ A phenomenological study of formative assessment in dance education}

\author{
Ninnie Andersson ${ }^{1}$ \\ Luleå University of Technology
}

\begin{abstract}
This article includes a study that examines how formative assessment in dance education is constituted in three Swedish upper secondary schools. The starting-point for the study is life-world phenomenology. A Phenomenological way of thinking entails that the human being is intersubjective, linked with and within the world and that learning requires the bodily subject's active experience. To turn towards the things themselves and to be open and adherent to things in the world is a basic rule and the starting point for research within phenomenology. This study is based on empirical material from observations of the phenomenon formative assessment in dance. Spiegelberg's philosophical method was used as a base for phenomenological analysis. The analysis results in three themes: modes of communication, dance-related knowledge and function of formative assessment. Formative assessment was observed in the study to commonly involve teachers' verbal communication and visualisation. The assessment practice is a continuous activity and very rarely involves any kind of self-assessment or tests. The results were discussed and related to a life-world phenomenological view of learning and earlier research.
\end{abstract}

Keywords: dance education, assessment, formative assessment, Upper secondary school

\section{Introduction}

This paper presents a study about teachers' assessment of dance knowledge in Swedish upper secondary schools. The focus is on teachers' experiences of formative assessment in dance, through classroom observations, with an analysis based on life-world phenomenology. Teachers in Swedish upper secondary schools are required to assess their students according to related steering documents (Swedish National Agency for Education, 2011). Assessment is an essential, extensive component of teaching, and in order to assess, teachers must be aware of the specific knowledge that needs to be assessed (Cone \& Cone, 2013). Their next challenge is how to assess and the identification of assessment validity (Blumenfeld-Jones \& Liang, 2007; Eisner, 2007; Gardner, 2012; The SAF

\footnotetext{
${ }^{1}$ Department of Arts, Communication and Education, Luleå University of Technology, 97187 Luleå, e-mail: ninnie.andersson@ltu.se
} 
Foundation \& Swedish Teachers' Union, 2010). The research area of assessment in dance provides international research and additionally relevant research about assessment in other subjects. Assessment in dance in Swedish upper secondary schools is almost completely unresearched, and this study attempts to address this research deficit. The overall aim of this study is to explore how formative assessments in dance education are constituted. To pursue this aim, the study asks three research questions: what teaching and learning goals are made visible? In what ways does the teacher make student achievement visible in relation to the goals of the course? In what ways does the teacher indicate what the students need to be aware of to improve their achievement in the course?

\section{Background}

\section{Dance knowledge in the course Dance Techniques 1}

In 2011, Sweden implemented Gy11, a new curricula and grading scale, including new syllabuses in the upper secondary school system (Swedish National Agency for Education, 2011). Dance knowledge in the Gy11 syllabuses is seen from a holistic perspective whereby dance is understood as a form of expression. The course Dance Techniques 1 covers parts of the overall domain of dance knowledge in Gy11. The value implication of what is important in the subject of dance is already decided, and there is an appraisal of what knowledge should be represented in this specific course in the context of the larger domain of dance. The students are expected to approach knowledge as performers, using the generic abilities of discovery, investigation, reflection and training. The subject-specific areas covered in the syllabus are dance quality, approach/attitude and technique (Swedish National Agency for Education, 2011). In the field of education, a comprehensive and equal assessment of holistic aesthetic knowledge is complex (Ferm Thorgersen \& Zandén, 2013). Despite the fact that teachers handle different forms of knowledge, they are expected to offer a balanced review in order to generate the possibility of different interpretations.

In accordance with this holistic view of knowledge, the teacher creates assessments based on a general impression of student achievement. This assessment should, with support from the syllabus' formulations of explicit aspects of the entirety of dance knowledge and knowledge requirements, resist the use of checklists (Swedish National Agency for Education, 2001). The Swedish National Agency for Education (2012) thus emphasises the importance of making an overall judgement of student achievement.

\section{Educational assessment}

Assessment is a complex assignment, a social phenomenon in which the understanding between the student and the teacher is important (Gipps, 1999; The SAF Foundation \& Swedish Teachers' Union, 2010). Assessments of student learning could be seen as multilingual, thus requiring more than a letter grade, and should include a narrative evaluation of their learning (Eisner, 2007). In the arts, adequate thought should be given to determine the qualities of the abilities under assessment. Assessment based on clear reasons might require a method other than, for instance, tick-box forms. Educational assessment is commonly divided into summative and formative assessment or assessment of learning and assessment for learning (Gardner, 2012). As Gardner (2012) observes, formative assessment dates back to 1967 while assessment for learning is a more modern concept. The Assessment Reform Group (2002, p. 2) describes assessment for learning as ' ...the process of seeking and interpreting evidence for use by learners and their teachers, to identify where the learners are in their learning, where they need to go and how best to get there'. According to Gardner's (2012) argument, assessment for learning is less likely to be used to describe summative assessment and more likely to include the 
concept of formative assessment. Based on the Swedish Ministry of Education's conceptualisation of the assessment practice, I have chosen to use the term formative assessment instead of assessment for learning.

\section{The phenomenon of formative assessment}

The Swedish National Agency for Education (2011) describes formative assessment as a tool for students and teachers to enhance student learning. Several researchers have stressed that formative assessment can improve student learning (Gardner, 2012; Hattie, 2009; Sadler, 1989). The significance of being conscious about the student's perspective within education has been emphasised by Hattie (2009) who also stresses the importance of explicitness regarding the aims of education, the criteria as well as the importance of varying the forms of teaching and feedback. Formative assessment is used to assist the student with taking the next step in his/her learning process (Gardner, 2012). The practice of assessment requires that the goals of education are made explicit, that it develops a consciousness of where the students are in relation to the course goals and how students can reach a higher level of achievement in the course (Swedish National Agency for Education, 2011). Formative assessment can be seen as the use of judgement as it is intended to shape and improve the student's proficiency (Sadler, 1989). Rubrics can be used to quantitatively evaluate complex performances and assist formative assessment (Warburton, 2010). According to Black and Wiliam (2009), evidence and decisions are connected in classroom practice:

Practice in a classroom is formative to the extent that evidence about student achievement is elicited, interpreted, and used by teachers, learners, or their peers, to make decisions about the next steps in instruction that are likely to be better, or better founded, than the decisions they would have taken in the absence of the evidence that was elicited. (Black \& Wiliam, 2009, p. 9)

The concept of feedback can be seen in numerous formulations relating to formative assessment (Black \& Wiliam, 2009; Gardner, 2012; Klapp Lekholm, 2008; Sadler, 1989). Definitions of feedback include both the informational content as well as the effect of the feedback (Sadler, 1989). Since feedback is designed to alter the achievement level of the student, one way to define it is to look at it as a gap between the student's current achievement level and a referenced level (Ramaprasad, 1983). Additionally, Sadler (1989) describes how a feedback loop should define what the student should learn, defines and communicates an excellent performance as well as how to improve an inadequate performance. Formative assessment takes place when teaching is modified to respond to students' needs (Gardner, 2012). In dance education, there can be a tendency for students to rely on teachers' feedback rather than their evaluation (Leijen, Lam, Wildschut, Robert-Jan Simons, \& Admiraal, 2009). Students' reflection can improve body awareness and develop dance skills. The task of giving all students within a dance class individual attention as well as regular, adequate and accurate assessment is significant for teachers (Kassing \& Mortensen, 1981). In group activities, such as dance, an awareness of offering equivalence in assessment is needed though the performance to be assessed can appear in various forms (Brown, 2004).

The validity of the assessment can challenge the appreciation for the value of knowledge. One way to look at validity in formative assessment is to ascertain whether stimulation to further learning has been achieved as a consequence (Stobart, 2012). Validity can be described as an indication of how well a test measures what it is intended to measure and the specific purpose with the test (Cureton, 1951). The meaning of the concept of validity has been enlarged from a theoretical view to one which is more operational (Kane, 2006). The concept now embraces the entire assessment process, including 
consequences, and the soundness and trustworthiness of an assessment (Cronbach, 1971; Messick, 1993).

It is important to understand what to work towards as well as what a successful performance can be. This requires the teacher to communicate with his/her students. Students often depend on the teacher's decoding of the steering documents (Stobart, 2012). For teachers with a significant amount of experience in dance assessment, additional ways of collecting evidence will be available (Cone \& Cone, 2013). Importantly, the Council of Europe (2001) divides assessment into fixed-point and continuous assessment and argues that both forms have advantages and disadvantages. In dance education, it is not common to use standardised papers or tests for dance performances. In subjects other than dance, the student's achievements sometimes end up as an artefact which can be separated from the learner (Sadler, 1989). This artefact makes it possible for the teacher to go back to the work of the student in the process of assessment. In dance performance, the teacher cannot go back to an artefact in the assessment process in the same way. According to Sadler (1989), a video recording of a student's performance is different in character from the primary performance. Performance assessments take place during the actual performance (Klapp Lekholm, 2008).

Cone and Cone (2013) emphasise that the question of who will perform the assessment needs to be addressed: is it performed by the teacher, is it peer-to-peer, or is it a self-assessment? It is recommended that a variety of methods for assessment in dance are used, for example, tools such as documentation of students' performances, self-assessment and an evaluation of the teaching performance (Hernandez, 2013). Teachers' reflections are important in improving teaching practice (Warburton, 2010). Ross and Mitchell (1993) emphasise the importance of verbal communication between the teacher and the student to foster insights into the student's capacity to think about the art form. Verbal feedback during class and after a performance can be described as an oral quantitative evaluation technique (Hernandez, 2013). Students more often express their learning through demonstration rather than through explanation (Alter, 2013). The students in Ross and Mitchell's (1993) study understood that evaluations based on video recordings helped them visualise their performance and develop a more profound understanding of peer and teacher evaluations, including their own. A study on video-based learning points out that students felt that video recordings were effective in self-assessment (Leijen et al., 2009). Moreover, Gipps (1999) emphasises that teachers' and students' mutual involvement in the assessment process is important.

\section{Life-world phenomenology as a base for educational assessment}

Based on a life-world phenomenological way of thinking, the subject is seen as the living body, and a life-world phenomenological approach allows the body to represent something more than just the physical body. The body comprehends the body-mind-soul, which constitute an entirety (MerleauPonty, 2006). Merleau-Ponty $(2006,1962)$ describes the lived body as a subject-object. When I experience the world with my dance in front of other people, I am the subject and object simultaneously: a subject by being-the-world with my dancing and an object by other people experiencing my dancing. The subject coexists with people in the world in the form of intersubjectivity. The subject experiences other people as psycho-physical, social and historical entities that cannot be separated from each other or from the world. One conclusion is that this intersubjectivity is, in accordance with life-world phenomenology, a prerequisite for learning to take place. A life-world phenomenological way of thinking follows that human beings are intersubjectively linked with and within the world. The intersubjective human being is a condition of the assessment practice, a practice which is also a social activity. The space of learning is something experienced as 
the subject of our lived body. The different horizons that these spaces offer are in coexistence with other subjects in the space.

According to Merleau-Ponty (1962), the only way to gain an insight into the world is through the human experience of it; I have access to the world through the lived body. Through active experience, the bodily subject can acquire knowledge. The whole body is included in a learning process. In dance, the whole human being experiences and expresses dance knowledge (Alerby \& Ferm, 2006). From the life-world phenomenological way of thinking, knowledge in dance consists of several interdependent dimensions of knowledge as well as where experiences take place in the world (Alerby \& Ferm, 2006). In dance, one is the beholder, the performer, the creator or a combination of these different aspects of participation.

\section{Methodology to Grasp the Phenomenon}

To be able to grasp the phenomenon of formative assessment in dance, material was gathered through classroom observations using field notes and video recordings. The subject of the phenomenological study was the observed teacher. The material generated constituted a basis for the analysis and created opportunities to capture different perspectives of the phenomenon. A basic rule and the starting point for research within life-world phenomenology is to turn towards the things themselves and to become an adherent to them. To grasp the phenomenon as it occurs, I turn towards the things themselves. I used the method that was intended to grasp the whole thing without narrow delimitations.

\section{Context of the study}

The classroom observations took place during two semesters in three Swedish upper secondary schools offering the course Dance Techniques 1 (Swedish National Agency for Education, 2011). To capture different perspectives of the phenomenon and provide a wide base for analysis, I chose schools with different conditions: cutting edge education, a state school and a private school. The selection ensured geographic and demographic dissimilarity. Among the requirements were that the school would offer the course Dance Techniques 1 for first-year students, allow me to make observations regularly and that the teachers selected should actually be teaching the course. Five teachers were selected, and three different dance genres in 24 lessons were observed. Two lessons from each school were video recorded.

During each classroom observation, I hand-wrote structured field notes, which were later transcribed in six cases with support from the video recordings. During the observations, I sat in a corner of the room to minimise the affect on the classroom activities. Despite this, I was always part of the classroom activity. The video camera was directed from the opposite angle to grasp information that I might miss from my own position. I observed the phenomenon over a long period. In accordance with Ferm (2004) and with reference to Schutz, this is a prerequisite for the study of a process like didactic interaction. More importantly, I needed to be aware that my presence in the classroom could affect the phenomenon. It was my intention to be an adherent and as open as possible to the phenomenon in order to reduce the impact of my presence on the classroom activity. However, regardless of my intentions, it is imperative to always be conscious of the potential risks.

\section{Analysis of material}

The method used to analyse the material was inspired by Spiegelberg's (1960) stages of phenomenological analysis. It was originally a philosophical method (Spiegelberg, 1960). In the following analytical process in this study, the phenomenon is seen and broadened out, varied and then 
condensed to find the essence of the phenomenon of formative assessment in dance. The stages can be seen as guidelines in this analytical process where the researcher might not need to follow them in strict chronological order (Alerby, 1998; Ferm, 2004). In accordance with life-world phenomenology, it is important to be adherent to the phenomenon. To do so, and in order not to force the phenomenon into a fixed structure, I chose not to follow the analytical method in strict chronological order. I first gathered material and then, through interpretation, I was able to crystallise the themes of the phenomenon.

At first, I let the phenomenon of formative assessment in dance reveal itself to me and allowed various aspects to show themselves through the formulations in my field notes. Three preliminary themes crystallised, and the relations between aspects and within the theme were investigated. I created an image of the general essence of the phenomenon as it revealed itself through the formulations in the field notes (see Figure 1). The image illustrated both the complexity of the phenomenon and the intertwining of the themes. Each aspect was related and compared to the others through similarities and differences. The constitution of each aspect was investigated to refine the specific essence of each theme which, in some cases, changed the content within the theme.

I interpreted how the essence of the phenomenon of formative assessment in dance was seen. How are the relations constituted between the different dimensions of the phenomenon and their aspects? What limitations of and possibilities for formative assessment in dance might emerge? How does the phenomenon relate to validity? This is presented in the discussion section of this paper.

\section{The Phenomenon of Formative Assessment in Dance}

Based on the phenomenological analysis, three themes of the phenomenon of formative assessment in dance emerged: function of formative assessment, modes of communication and dance-related knowledge (see Figure 1). Various aspects constituted these themes. The different themes and aspects of the phenomenon should not be seen as distinguished from each other but as various sides of the phenomenon that could be interwoven. These sides always exist but can be illuminated and combined with each other in various ways.

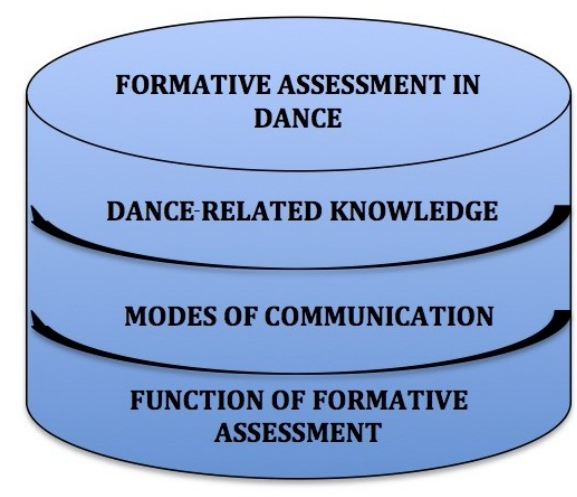

Figure 1. Image of the three themes of the phenomenon of formative assessment in dance. 


\section{The function of formative assessment}

The theme function of formative assessment was observed in the teachers' actions in the formative assessment practice in dance. I could see various aspects of the theme function of formative assessment in the material: teaching goals, student achievement, action to improve achievement and nonconstructive feedback. Each aspect consisted of specific traits and could be both distinguished from and intertwined with each other. This appeared to be reliant on what aspects of the theme the teacher expressed. In some cases, it was observed that the teachers expressed a specific aspect of the theme, and in others, the teachers emphasised various aspects concurrently, which intertwined the theme's aspects.

The aspect teaching goals was seen when the teacher variously expressed the goals of the dance class. The teachers never referred to the goals outlined in the syllabus, but my earlier experience of the syllabus helped me get glimpses of these formulations, for example, when the teacher embodied how the students should be aware of the room and the people in it. Student achievement was based on the students' achievement in relation to the goals of the course and was manifested in the way that the teacher identified this achievement. This aspect included general feedback both to the entire group and to individual students. Action to improve achievement was defined as how the teacher made the student aware of how to improve. Also included in this aspect was the teacher's communication as to how the student could improve his/her performance. Non-constructive feedback covered feedback that was unclear in terms of what it was based on, for example, a positive verbal or visual acknowledgement that something was performed well but without sufficient explanation of what this actually meant, such as when the teacher verbally communicated nothing more than the word 'good' to the whole group or to an individual student.

\section{Modes of communication}

Modes of communication grasps the teachers' communicative aspect of formative assessment. This theme included the aspects: significance of sound, use of body contact and visual part of communication. These aspects were distinguished from each other as well as in combination with one another, that is, intertwined. The significance of sound included verbal communication using words, rhythmical sounds and body sounds. The words were expressed with different intonations, force and volume, depending on the teacher and the situation. Rhythmical sounds were made by mouth, and body sounds included snaps and claps. Body and rhythmical sounds were seen as highlights within the quality and timing of the movement, commonly used to mark the beat of the music or the rhythm pattern of the exercise. The use of body contact included changing the student's postures through physical contact, such as when a teacher used pressure and force to move the arm from one position to another; it also appeared between teacher and student in the form of contiguity. The visual part of communication appeared as the teachers' embodied actions, images (pictures) and video recordings of the students. The teachers used their own bodies to demonstrate postures, patterns, movements and qualities. A picture was used to imagine the energy of a person's movements in relation to the room. Video recordings of the students' own performances and exercises were shown to them.

\section{Dance-related knowledge}

Dance-related knowledge embraces the knowledge that teachers focused on in the formative assessment practice. The intertwined aspects that emerged within this theme were ability to embody dance technique, nuances of movement, physical science in dance, relation to music in dance, conventions in the classroom of dance and reflection in and about dance performance. The ability to 
embody dance technique covers placement with reference to positions and technique concerning movements. This aspect involved dance techniques regarding how the body could be seen in static positions as well as the proficiency and ability of dance movement. Nuances of movement were seen both as generic dimensions of dance genres and specific dimensions of dance genres, including qualities, idioms and spatial abilities. Qualities and idioms were intertwined to such an extent that it was impossible to separate them. Idioms were seen as the form of the performing body, and quality was seen as different qualities of movement regarding weight, time, force and flow. Spatial ability was constituted by dance both in relation to the physical room and other subjects in the room. Physical science in dance encompassed the function of the physical body and the process of training dance. Processes of training included emphasis on different parts of the process and where and how the students could relate to these phases. Memorisation dominated the aspect of physical science in dance while relation to music in dance included the dimensions of rhythm, pace and style, which encompassed relations between the music and the performance. Knowledge of rhythm referred to how the dance material was rhythmically put together, which could involve counting different movements. Pace was the speed at which the dance material was to be performed. The teachers used different musical styles which affected and influenced the dance performance. In conventions in the classroom of dance, dimensions relating to discipline emerged in connection with attention level and the group's dress code. Attention in the classroom was demonstrated by the students' focus on the teachers' communication of the dance material or on other students' questions or corrections. The dress code included how the students arranged their hair or whether their clothing made it possible for the teachers to see their bodies clearly. Reflection in and about dance performance referred to the students' own development and achievement in different aspects of dance, such as when a teacher encouraged students to reflect on what they had achieved with respect to the goals of the course.

\section{Formative assessment - combinations of the themes in action}

The teachers combined different modes of communication with aspects of the themes of the function of formative assessment and dance-related knowledge. The communication to the students was both individual and general in the presentation of a satisfactory performance, the difference between a satisfactory and an unsatisfactory dance performance, corrections and negation. The themes were combined in various ways, and the aspects of these themes were often intertwined. The teachers used the mirror in their visual communication with the students, both for their own demonstration of performance and for the students to see their own and other students' performances. All three themes were incorporated with at least one aspect per theme in the formative assessment in dance. There was always some sort of dance-related knowledge involved with at least one aspect of the function of formative assessment that was communicated in at least one mode of communication. The themes were not separated from each other and appeared in various combinations. For example, when the aspects of the function of formative assessment emerged in combination with reflection in and about dance performance, the action was interwoven to communicate the ability to embody dance technique and nuances of movement.

In the function of formative assessment, verbal communication appeared in words, including different body parts. I could not identify which aspect of the function of formative assessment or dance-related knowledge that the verbal communication related to. The physical contact and visualisations were sometimes difficult to interpret although they could have the same consequences. For instance, the teacher could place a hand on the student's lower back, but the intention regarding the function of formative assessment or the dance-related knowledge could not be identified. 
In goals of the course, the classroom work mainly included verbal and visual modes in relation to all aspects of the theme dance-related knowledge and was always in the form of general feedback directed at the entire group of students. Action to improve achievement also consisted of all the aspects of dance-related content, but there was a difference in the use of modes, and included both general and individual feedback on how to improve student achievement. All modes of the teachers' communication appeared in the function of formative assessment but varied within the various aspects of dance-related knowledge. The most common mode was verbal communication where the teacher explained the movement with words or rhythmical sounds. Rhythmical sounds often related to dancerelated knowledge or the relation to music in dance. Only in the dance-related knowledge regarding nuances of movement, which focused on idioms and quality, did all modes emerge. The teachers' visualisation could also be seen quite extensively and often in combination with verbal communication. All concepts were expressed through the mode of verbal communication and at least one aspect of the visual part of communication. Nuances of movement, relation to music in dance and conventions in the dance classroom included more dimensions of the mode of rhythmical sounds and body sounds than verbal communication. The use of body contact was often seen in this aspect of the phenomenon.

In relation to student achievement, all aspects of the theme dance-related knowledge included both general and individual feedback except the content of reflection in and about dance performance, conventions in the dance classroom and nuances of movement. Only the ability to embody dance technique and nuances of movement regarding idioms and qualities included other modes of communication beyond verbal communication. The ability to embody dance technique included the visual part of communication from the teacher while idioms and quality were visualised in the video recordings of the students.

Physical science in dance and conventions in the dance classroom included the function of the physical body most often seen through the teachers' verbal communication in combination with the visualisation of embodied action, such as when the teacher explained a function of the body while demonstrating the action through embodiment. The teachers commonly used the terminology of dance movements and the order of the exercises.

In relation to music in dance, rhythms were commonly seen through the teachers' use of rhythmical sounds and body sounds, such as snaps and claps, using these to accentuate the movements that in many cases were intertwined with nuances of movement. In addition, style could frequently be seen in relation to nuances of movement.

\section{Summary of the phenomenon of formative assessment in dance}

The formative assessment practice in dance can be seen as a complex phenomenon whereby embodied dance knowledge constitutes the basis of what should be assessed. The phenomenon appeared as three themes, function of formative assessment, modes of communication and dance-related content, which could be seen as necessary dimensions of formative assessment in dance. These themes are intertwined and can be combined in various ways; this weaving together of themes emerges as meaning within the phenomenon. No use was made of written communication during class by either the teachers or the students, but one teacher referred to a journal that the students wrote outside of the lesson.

Communication regarding the students' achievement appeared to be multimodal in the form of the significance of sound, body contact and visual communication. The different dynamics in and quality of the teachers' multimodal expressions gave the actions different meanings to the student. This 
interpretation of meaning is dependent on the level of accord between the teacher and the student, which allows the communication to be meaningful for the student; without it, there is a huge risk that the student fails to understand the communicated formative assessment.

The teachers' actions in the formative assessment practice did not explicitly elucidate the goals of the teaching, but the goals were implicitly expressed in the teachers' actions. I was able to see the course goals in the teachers' actions, but they did not refer to the goals of the course. Some communication was not constructive though it did not explicitly refer to a particular function or dancerelated content.

\section{Discussion and Further Thoughts on Formative Assessment in Dance Education}

Here, I further discuss and relate the findings on formative assessment in dance to earlier research and life-world phenomenology. The teachers' use of different modes regarding the functions of formative assessment and dance-related content are discussed in relation to challenges in assessing dance and equal assessment. The discussion is presented through the following areas: communication about the goals of the course, moment of assessment, quality of feedback and dance as a group activity.

\section{Communication about the goals of the course}

Through the observed teachers' visual performance and verbal communication of the dance material, the students could understand the goals of the course. It is important that the students know what they are working towards and have the knowledge of what a successful performance can be (Sadler, 1989). The importance of explicit course aims and explicit criteria has been emphasised by several researchers (Hattie, 2009; Swedish National Agency for Education, 2001, 2011, 2012). Teachers are expected to embody an approved performance or communicate this expectation using other modes. Communicating the goals is very important and is often dependent on the expertise of the teacher, his/her communication skills, and his/her communication of the course content. One aspect of learning in dance is imitation of movement; that is, learning happens from body to body. It is therefore necessary that the movement, posture, expression, presence etc. be imitations that give the students information about the goals. According to life-world phenomenology, the whole body is included in the learning process (Alerby \& Ferm, 2006), and the lived body is a part of learning. In the space of learning, the student experiences dance as the subject of his/her lived body in coexistence with other subjects in the room. None of the teachers referred to the specific goals of the course through the verbal or visualised communication of the material. The students needed to relate the goals of the course by themselves though I could see the course goals being expressed without overt descriptions. The understanding between the student and the teacher that Gipps (1999) emphasises is an important factor in this social phenomenon. As Stobart (2012) observes, students often depend on teachers' decoding of the steering documents. This is necessary because the documents are sometimes difficult for students to understand. Teachers require good communication skills and the ability to interpret the construct of an assessment.

\section{Moment of assessment}

The moment of assessment refers to the point at which the assessment takes place. This period could differ in length. In an upper secondary school context, students usually study several courses while the teachers teach and assess at least as many different courses. Is it realistic to think that both teachers and students can memorise the goals of each course? This is a major challenge for students and 
teachers, yet it is a condition for valid formative assessment. I cannot see how it is possible to continually assess without knowing specifically what is to be assessed and the unique grading criteria. Only one of the observed schools referred to a test on the students' achievement at the end of the course. In this case, the class performed as a whole while two teachers observed and assessed them. I did not personally observe this class, but the teacher referred to it in another class I observed. The formative assessment during those observations occurred continuously in the classroom on the basis of the material provided by the teacher. On the one hand, the consequence is that the student is continually being assessed without the specific material, goals or abilities on which to focus. Assessing without the use of a checklist and communicating what is assessed and when present a challenge. On the other hand, there are many challenges as to whether tests or examinations truly reflect the domain. Is the test really measuring what is intended (Cureton, 1951)? If the students' technique in jazz dance is to be tested according to the syllabus, the teacher can create material that provides the students with the opportunity to fulfil the criteria. It is important to reflect on the consequences as well as the soundness and trustworthiness of assessments when different occasions for assessment are created. Are the students able to show their achievements in the course? Does the task/test/performance etc. require relevant abilities? When and how often are students assessed? How does a teacher get a picture of the entire domain to be assessed? Does the test or examination underrepresent the domain?

\section{Quality of feedback}

An essential part of formative assessment is the feedback given to students (Black \& Wiliam, 2009; Klapp Lekholm, 2008; Sadler, 1989). In this study, I saw non-constructive feedback given verbally as single adjectives like 'good', 'nice' and 'better'. These comments communicate positive feedback to students but say nothing about the goals of the course, where the students are in relation to the goals or how the students should continue working towards the goals. This lack of clarity is also common in verbal corrections, such as 'stronger centre' or 'spread out your feet'. The student gets an indication that something should change to reach the course goals but does not receive detailed information about how. Additionally, can the teacher be sure that the student really understands what he/she needs in order to change? Does the student get the message? What does the term 'strong centre' mean? Where is the 'centre' located? If validity in formative assessment is about supporting further learning (Stobart, 2012), validity might have failed in such cases. I was not able to identify the meaning of that feedback or whether the teacher and/or student had a mutual comprehension of its meaning from earlier experiences.

Hernandez (2013) and Ross and Mitchell (1993) address verbal communication in feedback, and the latter study points to the possibility of gaining an insight into the student's thoughts about the art form. One requirement is the student's ability to express those thoughts verbally. Alter (2013), on the other hand, describes the use of demonstration as when students show their learning. If the whole body is included in the learning process, how is it that this knowledge can only be represented in verbal communication? Is it possible that students have adequate reflections and can express themselves in their performances? I believe it is important for teachers to reflect on which methods of communication are offered to students and how those can improve student achievement. Two of the teachers had their students either reflect in a group, view themselves in video recordings once or twice during class or through the use of a journal. In some cases, this might be useful and necessary with verbal or written assignments, and sometimes, this might also be able to express reflections through other modes, such as embodied actions. Teachers' reflection is an important part of improving dance education (Warburton, 2010). 
The observed teachers commonly used general feedback directed at the entire group. The students needed to select for themselves whether that feedback was relevant to them and whether it was useful to pay attention to it. Based on the same principle of awareness of what could be individually useful, even individual feedback could work as general feedback for the rest of the group. Embracing this feedback could be a challenge if the students are not conscious of their own level of knowledge and achievement or if the student and the teacher do not have accordance on the meaning of the feedback. Understanding between the teacher and student is important (Gipps, 1999; The SAF Foundation \& Swedish Teachers' Union, 2010). It seems almost impossible for the teacher to know how each student reflects upon his/her own achievement level and how he/she embraces general feedback. My own experience, both as a student and teacher, is that general feedback to the entire class is commonly used in dance, and I suspect it is more a tradition than a well-thought-out pedagogical method. It seems that for feedback to be meaningful for the student, there has to be agreement about its meaning.

The teachers commonly used embodied actions and body contact, sometimes in combination with other modes, such as verbal communication. In Sweden, many teachers are required to apply written rubrics in their assessment practice, but I saw no signs of this in the observed dance classes. This could be one method used in formative assessment in dance (Warburton, 2013). The teachers used different modes of communication in their formative assessments, but no one used written communication in the classroom. One school worked with a journal outside the classroom where the students could reflect on different questions posed by the teacher. Can the non-verbal dimension of dance be represented in written form, or do these dimensions require other modes? As mentioned earlier, Alter (2013) argues that students more often express their learning through dance performance rather than explanation, thus suggesting that dance might require a way of working with rubrics that include embodied action instead of written communication. I believe this is an area to develop in dance though a rubric offers a way to capture a complex performance (Warbuton, 2013).

Sadler (1989) observes that one does not often get an artefact in dance that can be assessed unlike in, for example, a history class where students produce an essay or a test result or art students produce paintings or a sculpture. One cannot return to the performance to check for details or missed content. In dance classes, the students are required to grasp the feedback in the moment; they have nothing to use as a support in their learning process apart from the video recordings that in my observations were used in only two of the lessons. Teachers face the same dilemma; with the exception of video recordings, they have nothing to refer to. Sadler (1989) makes it clear that a video recording cannot be adequately compared with the primary performance; therefore, the assessment must happen in the moment. In the studies by Ross and Mitchell (1993) and Leijen et al. (2009), the students themselves thought that video recordings of their own dance performance helped them better visualise their performance. Cone and Cone (2013) argue that the more experience teachers have in dance assessment, the greater the means by which evidence can be collected. In this study, the collection of evidence in the classroom only appeared through the video recordings. I assume and hope that the teachers documented the students' achievements outside of class; but then this would only consist of the teachers' documented assessment, not evidence of the students' achievements. I believe that video recording in combination with methods such as peer-to-peer assessment and self-assessment could help students be more conscious of their learning process and can be used as a means by which evidence is collected for assessment. Reflection can be seen as an important activity to develop awareness and dance skills (Leijen at al., 2009). In dance, students can rely on teachers' feedback instead of their own evaluation, and I argue that video can be a method and a support basis for students. In accordance with Hernandez (2013), I maintain that the use of different methods for 
assessment in dance is preferable. I also believe that this will develop the assessment practice in dance and possibly contribute to a variety of teaching methods and the gathering of evidence of achievement. Life-world phenomenology posits that the subject's active experience is a condition for learning (Merleau-Ponty, 1962). Self-assessment can be one way for the bodily subject to grasp an experience of his/her individual achievement level, and as Leijen et al. (2009) emphasise, reflection is an important part of their learning in dance. One cannot rely only on video recordings as they are poor substitutes for primary performance (Sadler, 1989). Based on my observations, I can conclude that settings for conscious self-assessment by students were rare though I was not able to discern any of the reasons for this. As Cone and Cone (2013) state, in the variation of assessment methods, it is relevant to decide who is making the assessment and with what consequences; the soundness and trustworthiness of the assessment might emerge with these choices.

\section{Dance as a group activity}

Dance is often performed in groups, and students can perform different dance material because of the choreography. However, teachers commonly assess all students at the same time. Is it possible to do so and still obtain a valid assessment? This is a huge challenge for teachers as dance is most often taught and performed in groups, and teachers are obligated to give each student individual attention and make adequate assessments (Brown, 2009; Eisner, 2007; Kassing \& Mortensen, 1981). I see a validity issue regarding consequences, soundness and trustworthy assessment practices. To assess an entire group in one moment without an artefact could affect the assessment. Is it possible for a teacher to make accurate and adequate assessments under these conditions?

It should be noted that I only observed exercises performed in groups or by couples. Is it possible that working individually with the students could be a useful complement in dance education? In music education, individual teaching is more common. To work with assessment and the students' own consciousness of knowledge, individual teaching could be a complement to group teaching and the assessment practice. To develop the professional role of an assessor, I believe that consciousness and analysis of one's own assessment practice is necessary. Discussions between teachers are one way to become more aware of their own practice. The students' involvement and discussions on the assessment practice are also important as a way of working towards transparency. I also strongly believe that further research on this matter could shed some light for teachers in terms of the different dimensions of assessment in dance.

\section{On the contributor}

Ninnie Andersson is $\mathrm{PhD}$-student in education at the Department of Art, Communication and Education, Luleå University of Technology (LTU). Her area of research is within the dance field with a special focus on assessment. She is coordinator of the dance teacher education at LTU, where she also teaches Simonson technique (jazz dance) and didactics. Ninnie is working as a teacher as well as lecturing within the field of dance and mathematics. Ms Andersson has published a teaching material in form of a dvd and a written guidebook (www.dansiskolan.se). 


\section{References}

Alerby, E. (1998). Att fånga en tanke: en fenomenologisk studie av barns och ungdomars tänkande kring miljö [To catch a thought: A phenomenological study of the thinking of children and young people about the environment] (Doctoral dissertation). Luleå tekniska universitet, Pedagogik och ämnesdidaktik/Centrum för forskning i lärande.

Alerby, E., \& Ferm, C. (2006). Konsten att dansa eller dansandets konst-dans som förkroppsligad kunskap [The art of dancing and the dancing as art- dance as embodied knowledge]. In E. Alerby \& J. Elídóttir (Ed.) (pp. 157-170), Lärandets konst: betraktelser av estetiska dimensioner $i$ lärandet. Lund: Studentlitteratur.

Alter, J. B. (2002). Self-appraisal and pedagogical practice: Performance-based assessment approaches. Dance Research Journal, 34(2), 79-95.

Assessment Reform Group (2002). Assessment for learning: 10 principles. Research-based principles to guide classroom practice. Retrieved from October 13, 2013 from http://assessmentreformgroup.files.wordpress.com/2012/01/10principles_english.pdf

Black, P., \& Wiliam, D. (2009). Developing the theory of formative assessment. Educational Assessment, Evaluation and Accountability (formerly Journal of Personnel Evaluation in Education), 21(1), 5-31.

Blumenfeld-Jones, D., \& Liang, S. Y. (2007). Dance curriculum research. In L. Bresler (Ed.) International handbook of research in arts education (pp. 245-264). Springer: Dordrecht, Netherlands.

Brown, S. (2004). Assessment for learning. Learning and teaching in higher education, 1(1), 81-89.

Cone, S., \& Cone, T. P. (2013). Assessing dance in physical education. Strategies: A Journal for Physical and Sport Educators, 24(6), 28-32.

Council of Europe (2001). Common European Framework of Reference for Languages: learning, teaching, assessment. Retrieved October 13, 2013 from http://www.coe.int/t/dg4/linguistic/source/framework_en.pdf

Cronbach, L. J. (1971). Test validation. In R. L. Thorndike (Ed.), Educational measurement (2nd ed., pp. 443-507). Washington: American Council on Education.

Cureton, E. E. (1951). Validity. In E. F. Lindquist (Ed.) Educational measurement (pp. 621-694). Washington: American Council on Education.

Eisner, E. (2007). Interlude: Assessment and evaluation in education and the arts. In L. Bresler (Ed.) International handbook of research in arts education (pp. 423-426). Springer: Dordrecht, Netherlands.

Ferm, C. (2004). Öppenhet och medvetenhet: en fenomenologisk studie av musikdidaktisk interaktion [Openess and awareness - a phenomenological study of music teaching and learning interaction] (Doctoral dissertation). Luleå tekniska universitet, Musikhöskolan i Piteå.

Ferm Thorgersen, C. (2012). Lived music - Aesthetic experience from a life-world phenomenological perspective. Forthcoming, Philosophy of Music Education Review.

Ferm Thorgersen, C., \& Zandén, O. (2013). Teaching for learning or teaching for documentation? Music teachers' perspectives on a Swedish curriculum reform. British Journal of Music Education, submitted.

Gardner, J. (Ed.) (2011). Assessment and learning. SAGE Publications: Los Angeles.

Gipps, C. (1999). Socio-cultural aspects of assessment. Review of Research in Education, 24, 355-392.

Hattie, J. A. C. (2009). Visible learning: A synthesis of over 800 meta-analyses relating to achievement. London: Routledge.

Hernandez, B. (2013). The case for multiple, authentic, evidence-based dance assessments. Journal of Physical Education, Recreation \& Dance, 83(1), 5-56.

Kane, M. T. (2006). Validation. In R. L. Brennan (Ed.), Educational measurement (4th ed., pp. 17-64). Westport, CT: American Council on Education/Praeger Publishers.

Kassing, G., \& Mortensen, L. (1981). Critiquing student performance in ballet. Dance Research Journal, 14(1/2), 43-46.

Klapp Lekholm, A. (2008). Grades and grade assignment: Effects of student and school characteristics (Doctoral dissertation). Göteborg: Göteborgs universitet. 
Leijen, Ä., Lam, I., Wildschut, L., Robert-Jan Simons, P., \& Admiraal, W. (2009). Streaming video to enhance students' reflection in dance education. Computers \& Education, 52(1), 169-176.

Merleau-Ponty, M. (1962). Phenomenology of perception. London: Routledge.

Merleau-Ponty, M. (2006). Kroppens fenomenologi. Göteborg: Daidalos.

Messick, S. A. (1989). Validity. In R. L. Linn (ed.), Educational measurement (3rd ed., pp. 13-103). New York: American Council on Education/Macmillan.

Oreck, B. A., Owen, S. V. \& Baum, S. M. (2003). Validity, reliability, and equity issues in an observational talent assessment process in the performing arts. Journal for the Education of the Gifted, 27(1), 62-94.

Ramaprasad, A. (1983). On the definition of feedback. Behavioral Science, 28, 4-13.

Ross, M. \& Mitchell, S. (1993). Assessing achievement in the arts. British Journal of Aesthetics, $33(2), 99-112$.

Sadler, D. R. (1989). Formative assessment and the design of instructional systems. Instructional Science, 18(2), 119-144.

Spiegelberg, H. (1960). The phenomenological movement: A historical introduction. The Hague: Kluwer.

Stobart, G. (2012). Validity in formative assessment. In J. Gardner (ed.), Assessment and learning (2nd ed., pp. 233-242). London: Sage Publications.

Swedish National Agency for Education. (2001). Bedömning och betygssättning: kommentarer med frågor och svar [Assesment and marking: comments with questions and answers]. Stockholm: Swedish National Agency for Education.

Swedish National Agency for Education (2011). Curriculum for the upper secondary school. Retrieved from http://www.skolverket.se/publikationer?id=2705

Swedish National Agency for Education. (2011). Kunskapsbedömning i skolan: praxis, begrepp, problem och möjligheter [Assessment of knowledge in school: Praxis, concepts, issues and possibilities]. Stockholm: Swedish National Agency for Education.

Swedish National Agency for Education. (2012). Bedömning och betygsättning i gymnasieskolan [Assessment and marking in upper secondary school]. Retrieved from http://www.skolverket.se/publikationer?id=2841

The foundation SAF \& Swedish Teachers' Union. (2010). Bedömning för lärande: - en grund för ökat kunnande [Assessment for learning: - a basis for increased knowhow]. Stockholm: Foundation SAF in collaboration with Swedish Teachers' Union.

Warburton, E. C. (2010). From talent identification to multidimensional assessment: Toward new models of evaluation in dance education. Research in Dance Education, 3(2), 1. 